\title{
Effects of a six-month intradialytic physical ACTIvity program and adequate NUTritional support on protein-energy wasting, physical functioning and quality of life in chronic hemodialysis patients: ACTINUT study protocol for a randomised controlled trial
}

Justine Magnard ${ }^{1}$, Thibault Deschamps' ${ }^{1}$ Christophe Cornu', Anne Paris² and Dan Hristea ${ }^{2 *}$

\begin{abstract}
Background: Protein-energy wasting (PEW) is common in hemodialysis patients and is a powerful predictor of morbidity and mortality. Although much progress has been made in recent years in identifying the causes and pathogenesis of PEW in hemodialysis patients, actual management by nutritional interventions is not always able to correct PEW. Some investigators suggest that physical exercise may increase the anabolic effects of nutritional interventions, and therefore may have a potential to reverse PEW. The aim of this study is to investigate the effect of intra-dialytic progressive exercise training and adequate nutritional supplementation on markers of PEW, functional capacities and quality of life of adult hemodialysis patients.

Methods and design: Fifty end-stage renal disease patients undergoing hemodialysis, who meet the diagnostic criteria for PEW, will be randomly allocated into an exercise or control group for 6 months. The exercise consists of a progressive submaximal individualized cycling exertion using an adapted cycle ergometer, during the three weekly dialysis sessions. Biological markers of nutrition (albumin, prealbumin) will be followed monthly and all patients will be assessed for body composition, walk function, muscle strength, postural stability and quality of life at baseline and during the eighth week $\left(t_{+2}\right)$, the sixteenth week $\left(t_{+4}\right)$ and the twenty-fourth week $\left(t_{+6}\right)$ of the 6 -month adapted rehabilitation program.

Discussion: The successful completion of this current trial may give precious clues in understanding PEW and encourage nephrologists to extend prescription of exercise programs as well as therapeutic and as preventive interventions in this high-risk population.

Trial registration: The protocol for this study was registered with the France Clinical Trials Registry NCT01813851. Keywords: Hemodialysis, Protein-energy wasting, Nutritional supplementation, Intradialytic physical activity, Quality of life
\end{abstract}

\footnotetext{
* Correspondence: dhristea@echo-sante.com

${ }^{2} \mathrm{ECHO}$ Nantes, Centre de dialyse Laënnec, 23, rue des Piliers de la Chauvinière, 448000 Saint Herblain, France

Full list of author information is available at the end of the article
} 


\section{Background}

Nowadays, more than two million people are treated worldwide by dialysis for end-stage renal failure [1]. Despite significant progress in dialysis techniques and in the treatment of associated comorbidities, hemodialysis (HD) patients experience an impairment of their quality of life and have a much higher risk of mortality compared to an age-matched population. A sedentary lifestyle and an altered nutritional status have been identified as major risk factors for adverse outcomes in dialysis patients $[2,3]$.

Dialysis patients have decreased physical functioning (assessed by peak oxygen consumption ( $\dot{V} O 2$ max), physical performance tests, and self-reported functioning), diminished muscle mass and altered muscle quality, and all of these features are associated with an increased mortality risk [4-6]. These disturbances are directly related to renal failure and comorbidities, and also to adverse effects from medical treatments and from the dialysis itself. Dialysis induces notable metabolic changes: hypovolemia due to ultrafiltration, and rapid changes in electrolyte concentrations and systemic inflammation, which can all adversely affect physical function [7]. In addition, dialysis imposes immobilization over 12-18 hours a week, thereby directly contributing to sedentary behavior that can further worsen the medical condition of HD patients. This vicious circle can finally lead to the development of disability, loss of independence, and death [8]. For all these reasons dialysis patients have low levels of daily physical activity [9]. Therefore, it seems rational to promote programs for exercise training in this population.

In this vein, a large amount of literature published in the past 30 years has documented a myriad of potential benefits from exercise. Several include: increased maximal oxygen uptake capacity ( $\dot{V} O 2 \max$ ), improved blood-pressure control [10], decreased arterial stiffness [11], decreased systemic inflammation [12], improved solute removal by dialysis $[13,14]$, increased muscle mass, quality and force [15], and favorable psychological adaptations (e.g., higher perceived quality of life) [16]. Thus there is a large body of evidence that the impact of end-stage renal disease (ESRD) can be - for at least a significant part - counteracted by exercise training [7,17-20].

Along with this altered overall physical functioning, malnutrition is highly prevalent in the ESRD population, and is well-documented to be a strong predictor of mortality. Significant evidence comes from the data of large observational trials (USRDS, DOPPS [1-21]) showing that malnourished dialysis patients have an increased risk of mortality [22,23]. In this context, the International Society of Renal Nutrition and Metabolism (ISRNM) has recommended the term "protein-energy wasting" (PEW) to describe the loss of body protein mass and fuel reserves and have defined the diagnostic criteria for this state (see Table 1).
Table 1 ISRNM criteria for the clinical diagnosis of PEW in maintenance dialysis patients

\begin{tabular}{ll}
\hline $\begin{array}{l}\text { Serum } \\
\text { chemistry: }\end{array}$ & \\
& Serum albumin $<3.8 \mathrm{~g}$ per $100 \mathrm{ml}$ \\
& Serum prealbumin $<30 \mathrm{mg}$ per $100 \mathrm{ml}$ \\
& Serum cholesterol $<100 \mathrm{mg}$ per $100 \mathrm{ml}$ \\
Body mass: & \\
& BMl $<23$ \\
& $\begin{array}{l}\text { Unintentional weight loss over time: } 5 \% \text { over } 3 \text { months } \\
\text { or 10\% over } 6 \text { months }\end{array}$ \\
& Total body fat percentage $<10 \%$
\end{tabular}

Muscle mass:

Muscle wasting: reduced muscle mass 5\% over 3 months or $10 \%$ over 6 months

Reduced mid-arm muscle circumference area (reduction $>10 \%$ in relation to $50^{\text {th }}$ percentile of reference population)

Creatinine appearance

Dietary

intake:

Unintentional low dietary protein intake $<0.80 \mathrm{~g} \cdot \mathrm{kg}^{-1}$.day-1 for at least 2 months

Unintentional low dietary energy intake $<25 \mathrm{kcal} \cdot \mathrm{kg}^{-1}$. day-1 for at least 2 months

*At least three out of the four listed categories (and at least one test in each of the selected category) must be satisfied for the diagnosis of kidney disease related PEW. Optimally, each criterion should be documented on at least three occasions, preferably 2-4 weeks apart.

ISRNM, international society of renal nutrition and metabolism; PEW, proteinenergy wasting; BMI, body mass index.

All these criteria are individually associated with an increased risk of adverse outcome so it can be assumed that the concomitant presence of at least three criteria is an even more powerful predictor of morbidity and mortality. However, to the best of our knowledge, until now no report exists about the prevalence and clinical outcomes of PEW (as defined by the ISRNM). It can be noted, however, that a large observational French study reported that $36 \%$ of HD patients had a prealbumine $<300 \mathrm{mg} / \mathrm{dl}, 20 \%$ had albumin $<35 \mathrm{~g} / \mathrm{l}$ and $62 \%$ a diminished lean body mass (LBM) $<90 \%$ [24].

The mechanisms causing PEW are complex and multifactorial: low nutrient intake (sometimes due to dietary restriction), loss of nutrients into dialysate, abnormalities that stimulate protein degradation and/or decrease protein synthesis. On this last point, we can include the production of inflammatory cytokines, oxidative and carbonyl stress, endocrine disorders (hyperparathyroidism, hypogonadism, diabetes, decreased insuline/insuline like growth factor (IGF) signaling), acidosis, electrolyte 
imbalance, and anemia [25]. Further, low daily physical activity causes the loss of muscle mass and force and thereby directly contributes to worsen PEW. Traditional management of PEW according to international guidelines (coming from the EBPG working group on nutrition [26]) consists of dietary counseling, oral nutritional supplements, enteral feeding, and in severe cases, the use of intradialytic or total parenteral nutrition. Several studies, however, have shown that these interventions are not always able to correct PEW [27].

Simultaneously, considerable literature has pointed out the anabolic effects of physical activity. For example, both strength and endurance exercise induce transcriptional changes in genes (IGF, myostatin) favoring anabolic muscle [28]. Morevover, histologic and computed tomography studies have clearly demonstrated a decrease in muscle atrophy and an improvement of the overall muscular structure and quality (increased proportion of type II, oxydative fibers) [29]. There is also some evidence that intradialytic exercise, combined with oral or parenteral nutrition, enhances amino acid uptake and protein accretion in the muscles of HD patients [30,31]. Strong arguments exist for programming the adapted exercise training during the dialysis session rather than on non dialysis days, as there is better adherence by patients who feel safer doing exercise under medical monitoring, as a the counteraction to the inactivity due to the dialysis session, and due to a greater removal of uremic toxins (as shown for urea (KT/V) and phosphorous) by improved tissue mobilization. In addition, according to the large amount of published clinical trials, the risks of prescribing exercise even in this frail population are limited and the benefits largely prevail. Musculoskeletal injuries and cardio-vascular events are the most common risks of physical exercise. Both types of adverse events occur more frequently with high-intensity exercise than with submaximal exercise [32]. In this present trial, patients will be advised to exercise at a moderate level of perceived exertion and will be under continuous supervision by medical personnel. It should also be mentioned that European guidelines on nutrition in HD patients explicitly recommends regular physical exercise [26].

In sum, there are strong arguments in the literature to prescribe exercise in HD combined with nutritional interventions in patients suffering from PEW in an attempt to enhance the anabolic effects of nutrition and hereby reverse this high-risk state.

\section{Specific aims}

The aim of this randomized controlled trial is to analyze the impact of a progressive intra-dialytic exercise program combined with nutritional support following current guidelines on nutritional parameters defined for PEW and its potential to reverse PEW. In addition, this trial will study the effect of intradialytic exercise on functional performance (walking, postural control, and muscular strength), body composition and health-related quality of life in HD patients.

\section{Methods and design Study design}

This study is a multicenter, open-label randomized controlled trial. The study will be conducted at the outpatient HD Laennec Dialysis unit and Confluent Dialysis unit of the ECHO Dialysis Association. HD patients will be randomly distributed into a control or an exercise group. The randomization sequence of the participants will be generated by a computer program. A bio-statistician not involved in recruitment and assessment will perform the randomization.

The present study was approved by the Ethical Committee of Nantes Ouest IV (reference: ID RCB n ${ }^{\circ} 2012-$ A01662-41), and was conducted in accordance with the Declaration of Helsinki (last modified in 2004). All participants will receive written and verbal information about the aims and procedures of the study and will sign a consent form to participate in the study.

\section{Participants' recruitment}

All of the 210 patients treated by hemodialysis or onlinehemodiafiltration in the participating centers will be screened for the presence of criteria for PEW. The principal investigators will review the existing patients' database for serum albumin, serum prealbumin, C-reactive protein (CRP) levels, body mass index (BMI) and the presence of weight loss according to the PEW criteria. Potential subjects will have additional tests (measure of lean body mass index by bio-impedance and a 3-day dietary record by a qualified dietician in order to evaluate their protein and energy intake). Patients fulfilling inclusion/exclusion criteria and having signed an informed consent for the study participation will undergo randomization generated by a computer program. We expect to recruit approximately fifty HD patients for this study.

\section{Inclusion criteria}

- Adult patients, male or female (Age > 18 years).

- Minimum hemodialysis vintage of 3 months.

- Stable on HD, in gender.

- No recent hospitalization.

- No acute or chronic medical conditions that would make exercise training potentially hazardous or primary outcomes impossible to assess.

- Patients who meet the following criteria for PEW (according to [25]), meeting at least three out of the four listed categories and at least one test in each of selected category: 
- Serum chemistry criteria: Serum albumin level $<38 \mathrm{~g} / \mathrm{L}$ (Bromcresol Green), or serum prealbumin $<300 \mathrm{mg} / \mathrm{L}$,

- Body mass criteria: BMI $<23 \mathrm{~kg} / \mathrm{m}^{2}$, or unintentional weigh loss $>5 \%$ over 3 months or $>10 \%$ over 6 months,

- Muscle mass criteria: lean body mass (LBM) estimated by bioimpedance spectroscopy (Body Composition Monitor (BCM) Fresenius, Bad Homburg, Germany) lower than the $10^{\text {th }}$ percentile of an aged-matched normal population. This method is validated in dialysis patients $[33,34]$.

- Dietary intake criteria: Unintentional low dietary protein intake $<1 \mathrm{~g} / \mathrm{kg}$ of ideal weight/day for at least 2 months, unintentional low dietary energy intake $<30 \mathrm{kcal} / \mathrm{kg}$ of ideal weight/day for at least 2 months.

- Informed consent of the patient.

\section{Exclusion criteria}

- Contraindication or inability to perform the physical exercise.

- Inadequate dialysis $\mathrm{Kt} / \mathrm{V}<1.2$.

- Presence of a cardiac pacemaker (incompatible with the BCM measures).

- Systemic inflammation CRP $>20 \mathrm{mg} / \mathrm{l}$.

- Pregnant woman.

- Patient under guardianship.

- Participation in another clinical interventional trial.

- Unstable on dialysis.

\section{Intervention}

All the patients will continue their usual dialysis procedure (HD or HDF). No modifications of dialysis modality or prescriptions are allowed except for adaptation of dry weight using clinical criteria.

Both patients in the control and exercise groups will receive dietary counseling by a trained dietician. The prescription of oral nutritional complements or intradialytic parenteral nutrition will be adapted to patient needs according to the dietary record in order to attain goals set by the EBP guidelines for gender energy intake 30-40 $\mathrm{kcal} / \mathrm{kg}$ of ideal weight/day, and protein intake $>1.1 \mathrm{~g} / \mathrm{kg}$ of ideal weight/day.

\section{Exercise group}

A 6-month adapted rehabilitation program will be conducted by means of progressive submaximal individualized cycling exercise, consisting of three sessions per week. The exercise will be prescribed during the first two hours of dialysis session using an adapted cycle ergometer (« Reck moto-med letto ») that allows cycling in a supine position at different resistance levels. The cycle ergometer displays the number of revolutions per minute, the power developed and the distance virtually traveled. For the patient, these types of visual feedback are motivational factors that are recognized in the literature [35]. Further, it should be noted that this cycle ergometer also allows for passive motorized pedaling (i.e., the patient can pedal without effort).

The aim of this 6-month individualized program is to reach a 30 min duration of continuous cycling at a moderate exercise intensity, which corresponds to the level "3 - moderate" on the Borg Rating Perceived Exertion $(\mathrm{RPE})$ scale (graduated from 0 to 10 , where $0=$ no effort at all, and $10=$ most extreme effort imaginable). According to recommendations issued from a large scale metaanalysis [36], the exercise will be initially performed at this intensity exercise perceived as moderate by the patient on the RPE scale (i.e., level 3). We deliberately chose this method based on the patient's rating perceptions rather than a method based on the heart rate assessment because many dialysis patients have automatic impairment or drug treatments that can interfere with the heart rate control. This method is readily accessible, reproducible and easy to use. Several exercise training intensity levels at $50 \%$ to $85 \%$ of the maximal oxygen consumption correspond consistently to ratings of 3-7 levels on the Borg RPE scale [37].

To estimate the targeted moderate exercise intensity, an exercise protocol with an increasing intensity on the cycle ergometer will be performed at the inclusion, before the rehabilitation program. During this first evaluation, after a warm-up of 5 minutes without resistance, the patient will pedal with a self-selected chosen cadence against an increasing resistance imposed by the cycle ergometer, until the patient reaches a level perceived as moderate, namely level 3 on the Borg RPE scale. A similar monthly assessment will be realized to update the intensity of cycling exercise. During these sessions, the patient will be regularly asked about level of shortness of breath, any feelings of fatigue and pain, with a visual analogue scale $(0-10 \mathrm{~cm})$, in order to reduce the exercise intensity if necessary.

During a dialysis session, the cycling exercise will be performed in the first half of the session. After a $5 \mathrm{~min}$ warm-up without resistance, the patient will gradually reach the intensity corresponding to level 3 on the Borg RPE scale. Then the patient will be instructed to maintain this cycling exercise intensity for at least 10 minutes during the first month, 15 minutes during the second one, 20 minutes for the two next months in order to achieve the targeted exercise duration of 30 minutes in the two last months. The first target is to observe an evolution of their functional capacity/performance over time. Finally, a period of active recovery (pedaling 
without resistance) followed by a period of passive pedaling recovery will end the exercise session. Blood pressure and heart rate will be measured at the beginning and the end of the exercise session. Heart rate will be maintained below $70 \%$ of maximum heart rate during the cycling exercise. At the end of the dialysis session, the HD patient will be asked to estimate pain level, boredom level and mood as perceived during the session, with a visual analogue scale graduated from 0 to 10 . Nephrologists, nurses, and a specialist in adapted physical activities will monitor the patient.

\section{Control group}

Similarly, at the end of each dialysis session, the "control" patient will be asked to estimate his pain level, boredom level and mood perceived during the session, with a visual analogue scale graduated from 0 to 10 [38].

\section{Outcome measures}

All the measures listed below will be assessed at the baseline $t_{0}$, and during the eighth week $\left(t_{+2}\right)$, the sixteenth week $\left(t_{+4}\right)$ and the twenty-fourth week $\left(t_{+6}\right)$ of the 6 -month adapted rehabilitation program.

\section{Primary outcome measures}

The primary outcome of this study is the number of patients who are no longer in a state of protein energy wasting after 6 months of exercise training compared to the control group. We define correction of PEW as the normalization of albumin and prealbumine, and of the lean tissue index, considering these items to be the clinically most relevant for the diagnostic criteria of PEW.

\section{Biological sample}

Patients in both groups will have routine serum chemistry measures according to follow-up guidelines for dialysis patients in terms of serum electrolytes, -bicarbonate, s-urea and creatinine, urea reduction rate, KT/V monthly, PTH and $25 \mathrm{OH}$ vitamine $\mathrm{D}$, which will be measured at the beginning and at the end of the study. Patients will receive oral native vitamin $\mathrm{D}$ supplementation in order to maintain serum $25 \mathrm{OH}$ levels in the normal laboratory range.

\section{Dietetics survey}

Protein and energy intake will be assessed by a qualified dietitian by means of a 3 day food record at the beginning and at the end of the study.

\section{Secondary outcome measures}

Secondary outcome measures include: (i) changes in biological markers of nutrition (albumin and prealbumine), body composition (LTI, FTI), muscle strength, walk function, postural stability, quality of life, days of hospitalization, and survival.

\section{Biological markers of nutrition (albumin and prealbumine)}

Serum albumine and -prealbumine will be measured monthly. BMI will be calculated at month $t_{+2}, t_{+4}$ and $t_{+6}$. Serum albumine is measured by the bromcresol green method (normal range $(38-52 \mathrm{~g} / \mathrm{l})$, serum prealbumine is measured by the immune-turbidimetric method (normal range $300-400 \mathrm{mg} / \mathrm{l})$.

\section{Body composition}

Body-composition (overhydration, lean tissue index $\left(\mathrm{LTI}, \mathrm{kg} / \mathrm{m}^{2}\right.$ ) and fat tissue index $\left(\mathrm{FTI}, \mathrm{kg} / \mathrm{m}^{2}\right.$ ) will be measured by bioimpedance spectroscopy using a Body Composition Monitor (BCM, Fresenius Medical Care, Bad Homburg, Germany) at month 2, 4 and 6 just before the midweek dialysis session.

\section{Walk function}

The walk function assessment will be performed using a 6 min-walk-test (6MWT). This test has been considered to be an appropriate test to assess a patient's functional and physiological response and cardiovascular fitness [39]. Patients will walk along a measured circuit (15 m), and are instructed to cover as much distance as possible in the six minutes. Blood pressure, heart rate and rating perceived exertion (RPE) will be assessed before and after the 6MWT.

\section{Muscle strength}

Maximal quadriceps strength during a knee extension will be tested using a manual dynamometer (Metil Industry®, Belgium). Patients will perform three maximal leg extensions in sitting position before a dialysis session. At least five minutes of recovery will be provided between 2 consecutive measurements.

\section{Quality of life}

The self-reported quality of life will be evaluated using the Medical Outcome Study Short Form 36 (SF-36) [40-42], which has been documented to be reliable and valid in dialysis patients [10,43]. This SF-36 is a generic multidimensional instrument consisting of eight multiitem scales representing: (1) physical functioning (extent to which health limits physical activities, such as self-care, walking, and climbing stairs), (2) social functioning (extent to which physical health or emotional problems interfere with normal social activities), (3) role-functioning physical (extent to which physical health interferes with work or other dally activities), (4) role-functioning emotional (extent to which emotional problems interfere with work or other daily activities), (5) mental health (general mental health, including depression, anxiety, behavioral and emotional control, and general positive effect), (6) vitality (feeling energetic and full of pep rather than tired and worn out), (7) bodily pain (intensity of pain and effect of pain 
on normal work, both inside and outside the home), and (8) general health perceptions (personal evaluations of current health, health outlook, and resistance to illness).

\section{Postural stability}

Balance during a quiet stance will be tested after a rest period before the dialysis session. The postural test will consist of two conditions of quiet stance: stance on a firm surface with eyes open (EO) and stance on a firm surface with eyes closed (EC). Participants will stand quietly while barefoot, with the head in a straight-ahead position, their arms along the body. During conditions with eyes open, they will be instructed to look at a black spot (with a diameter $2 \mathrm{~cm}$ diameter) placed on a white wall in the front of them at a $2 \mathrm{~m}$ distance. For each condition, two trials will be performed. The duration of each trial will be $60 \mathrm{~s}$ followed by a rest period of 1 minute. During thee condition with EO, the subject's eyes will focus on a stationary eye-level visual target (a black spot with a $2 \mathrm{~cm}$ diameter) situated at a $2 \mathrm{~m}$ distance. For all data collection of postural sway, we will use a Kistler force plateform (model 9286BA) with subject weight normalization. Data will be sampled at $100 \mathrm{~Hz}$ and recorded online. The body sway will be quantified by displacement of the center of foot pressure (COP) in the anterior-posterior (AP) and in the medial-lateral direction (ML). For measuring all of the COP parameters, raw data will be filtered using a fourth-order Butterworth, zero-phase low-pass at $10 \mathrm{~Hz}$. The COP parameters will then be the mean and standard deviation (SD) of COP position in AP and ML directions, $\mathrm{SD}$ of velocity in AP and ML directions, mean velocity and area (90\% confidence ellipse) (see [44] for details of formulas).

\section{Statistical analysis}

The sample size was calculated considering the number of patients who are no longer in a state of protein energy wasting after 6 months of exercise training compared to the control group. For a significance level of 0.05 and $80 \%$ power, it was estimated that 22 participants would be required in each group.

Results will be expressed as minimum to maximum or percentage of change, as applicable, and mean \pm standard deviation. To test the effects of Group (Exercise versus Control) on all outcome measures, univariate two-way analyses of variance (ANOVAs), with the Group $(\times 2)$ as between-subjects factor and Time $\left(t_{0}, t_{+2}\right.$, $t_{+4}$ and $\left.t_{+6}\right)$ as the within subject factor, will be carried out for each aforesaid dependent variable. For each analysis, the level of significance was $p<0.05$. Newman-Keuls comparisons will be used for post-hoc tests following significant effects. If the sphericity assumption in ANOVA is violated (Mauchly's test), corrected tests of significance will be used $[45,46]$. In that case, the paired t-tests with corrected alpha level will be used as post-hoc comparisons. All the statistical analyses will be conducted using a SPSS software package.

\section{Discussion}

To our knowledge, this is the first trial investigating the impact of intradialytic exercise combined with an individualized nutritional support on protein energy wasting. It is also the first trial to investigate the influence of exercise on postural balance, which is of special interest for fundamental and clinical purposes (i.e., the important issue of physical condition in dialysis patients). An improved postural balance signifies a decreased incidence of falls and fractures in this high-risk population [47]. The main forces of this trial will be the randomized design and the individualized management of "real life" patients suffering from PEW. It can be argued that the nutritional support will not be the same in all patients as some will have only nutritional counseling and others ONC and a few IDPN. However, according to the literature the different nutrition methods have equivalent efficacy and the prescription of the type of nutritional support will follow actual guidelines. If this current clinical trial can highlight the expected effects of exercise to reverse PEW, at least for a part, it would be a strong argument for implementing an exercise program in this high-risk population and even in the whole dialysis population in order to prevent the occurrence of PEW.

\section{Competing interests}

Authors declare that there is no competing interest.

\section{Authors' contributions}

$\mathrm{DH}$ has conceived and designed the research protocol, DH and AP contributed in patients' inclusion-exclusion criteria and submission of the protocol to the ethics committee, while JM and TD have suggested important aspects for exercise protocol, functional measures and quality of life. The manuscript was prepared by $\mathrm{DH}, \mathrm{JM}$, and TD. All authors revised the manuscript critically for important intellectual content and approved the final version to be published.

\section{Acknowledgements}

The study was sponsored by the University Hospital of Nantes. The research is also sponsored in part by the ACTICLAN prize provided by Fresenius Kabi France.

The Body Composition Monitor is graciously provided by Fresenius Medical Care, France.

The Reck moto med ergometers are provided by Echo Nantes, Dialysis Association.

\section{Sponsor's role}

The study was financially supported by the Nantes University Hospital and by the ACTICLAN association. The sponsor had no role in the design and conduct of the study, in the collection, management, analysis, and interpretation of the data, or in the preparation, review, or approval of the manuscript.

\section{Author details}

'University of Nantes, Laboratory "Motricité, Interactions, Performance" (UPRES EA 4334), F-44000 Nantes, France. ${ }^{2} \mathrm{ECHO}$ Nantes, Centre de dialyse Laënnec, 23, rue des Piliers de la Chauvinière, 448000 Saint Herblain, France. 
Received: 31 May 2013 Accepted: 8 November 2013

Published: 26 November 2013

\section{References}

1. Grassmann A, Gioberge S, Moeller S, Brown G: ESRD patients in 2004: global overview of patient numbers, treatment modalities and associated trends. Nephrol Dial Transplant 2005, 20:2587-93.

2. O'Hare AM, Tawney K, Bacchetti P, Johansen KL: Decreased survival among sedentary patients undergoing dialysis: results from the dialysis morbidity and mortality study wave 2. Am J Kidney Dis 2003, 41:447-454.

3. Lopes AA, Bragg-Gresham JL, Elder SJ, Ginsberg N, Goodkin DA, Pifer T, Lameire N, Marshall MR, Asano Y, Akizawa T, et al: Independent and joint associations of nutritional status indicators with mortality risk among chronic hemodialysis patients in the dialysis outcomes and practice patterns study (DOPPS). J Renal Nutr 2010, 20:224-234.

4. Sietsema KE, Amato A, Adler SG, Brass EP: Exercise capacity as a predictor of survival among ambulatory patients with end-stage renal disease. Kidney Int 2004, 65:719-724.

5. Johansen KL, Shubert T, Doyle J, Soher B, Sakkas GK, Kent-Braun JA: Muscle atrophy in patients receiving hemodialysis: effects on muscle strength, muscle quality, and physical function. Kidney Int 2003, 63:291-297.

6. Moore GE, Parsons DB, Stray-Gundersen J, Painter PL, Brinker KR, Mitchell JH: Uremic myopathy limits aerobic capacity in hemodialysis patients. Am J Kidney Dis 1993, 22:277-287.

7. Cheema BS, Smith BC, Singh MA: Rationale for intradialytic exercise training as standard clinical practice in ESRD. Am J Kidney Dis 2005, 45:912-916

8. Johansen $\mathrm{KL}$ : Exercise in the end-stage renal disease population. J Am Soc Nephrol 2007, 18:1845-1854.

9. Johansen KL, Chertow GM, Ng AV, Mulligan K, Carey S, Schoenfeld PY, Kent-Braun JA: Physical activity levels in patients on hemodialysis and healthy sedentary controls. Kidney Int 2000, 57:2564-2570.

10. Painter P, Moore GE, Carlson L, Paul S, Myll J, Phillips W, Haskell W: Effects of exercise training plus normalization of hematocrit on exercise capacity and health-related quality of life. Am J Kidney Dis 2002, 39:257-265.

11. Mustata S, Chan C, Lai V, Miller JA: Impact of an exercise program on arterial stiffness and insulin resistance in hemodialysis patients. J Am Soc Nephrol 2004, 15:2713-8.

12. Cheema B, Abas H, Smith B, O'Sullivan A, Chan M, Patwardhan A, Kelly J, Gillin A, Pang G, Lloyd B, et al: Randomized controlled trial of intradialytic resistance training to target muscle wasting in ESRD: the progressive exercise for anabolism in kidney disease (PEAK) study. Am J Kidney Dis 2007, 50:574-84.

13. Kong CH, Tattersall JE, Greenwood RN, Farrington K: The effect of exercise during haemodialysis on solute removal. Nephrol Dial Transplant 1999, 14:2927-2931.

14. Farese S, Budmiger R, Aregger F, Bergmann I, Frey FJ, Uehlinger DE: Effect of transcutaneous electrical muscle stimulation and passive cycling movements on blood pressure and removal of urea and phosphate during hemodialysis. Am J Kidney Dis 2008, 52:745-752.

15. Kouidi E, Albani M, Natsis K, Megalopoulos A, Gigis P, Guiba-Tziampiri O, Tourkantonis A, Deligiannis A: The effects of exercise training on muscle atrophy in haemodialysis patients. Nephrol Dial Transplant 1998, 13:685-99.

16. Ouzouni S, Kouidi E, Sioulis A, Grekas D, Deligiannis A: Effects of intradialytic exercise training on health-related quality of life indices in haemodialysis patients. Clin Rehabil 2009, 23:53-63.

17. Heiwe $\mathrm{S}$, Jacobson SH: Exercise training for adults with chronic kidney disease. Cochrane Database Syst Rev 2011, 5, CD003236.

18. Giannaki CD, Stefanidis I, Karatzaferi C, Liakos N, Roka V, Ntente I, Sakkas GK: The effect of prolonged intradialytic exercise in hemodialysis efficiency indices. ASAIO J 2011, 57:213-218.

19. Maheshwari V, Samavedham L, Pandu Rangaiah G, Loy Y, Hsi LL, Sethi S, Lau L: Comparison of toxin removal outcomes in online hemodiafiltration and intra-dialytic exercise in high-flux hemodialysis: a prospective randomized open-label clinical study protocol. BMC Nephrol 2012, 13:156.

20. Oh-Park M, Fast A, Gopal S, et al: Exercise for the dialyzed: aerobic and strength training during hemodialysis. Am J Phys Med Rehabil 2002, 81:814-821
21. Canaud B, Tong L, Tentori F, Akiba T, Karaboyas A, Gillespie B, Akizawa T, Pisoni RL, Bommer J, Port FK: Clinical practices and outcomes in elderly hemodialysis patients: results from the dialysis outcomes and practice patterns study (DOPPS). Clin J Am Soc Nephrol 2011, 6:1651-62.

22. Fung F, Sherrard DJ, Gillen DL, Wong C, Kestenbaum B, Seliger S, Ball A, Stehman-Breen C: Increased risk for cardiovascular mortality among malnourished end-stage renal disease patients. Am J Kidney Dis 2002, 40:307-314.

23. Pifer TB, McCullough KP, Port FK, Goodkin DA, Maroni BJ, Held PJ, Young EW: Mortality risk in hemodialysis patients and changes in nutritional indicators: DOPPS. Kidney Int 2002, 62:2238-2245.

24. Aparicio M, Cano N, Chauveau P, Azar R, Canaud B, Flory A, Laville M, Leverve $X$ : Nutritional status of haemodialysis patients: a French national cooperative study: French study group for nutrition in dialysis. Nephrol Dial Transplant 1999, 14:1679-1686.

25. Fouque D, Kalantar-Zadeh K, Kopple J, Cano N, Chauveau P, Cuppari L, et al: A proposed nomenclature and diagnostic criteria for protein-energy wasting in acute and chronic kidney disease. Kidney Int 2008, 73:391-8.

26. Fouque D, Vennegoor M, ter Wee $P$, Wanner C, Basci A, Canaud B, Haage $P$, Konner K, Kooman J, Martin-Malo A, et al: EBPG guideline on nutrition. Nephrol Dial Transplant 2007, 22:ii45-87.

27. Cano NJ, Fouque D, Roth H, Aparicio M, Azar R, Canaud B, et al: Intradialytic parenteral nutrition does not improve survival in malnourished hemodialysis patients: a 2-year multicenter, prospective, randomized study. J Am Soc Nephrol 2007, 18:2583-91.

28. Kopple JD, Wang H, Casaburi R, Fournier M, Lewis M, Taylor W, Storer T: Exercise in maintenance hemodialysis patients induces transcriptional changes in genes favoring anabolic muscle. J Am Soc Nephrol 2007, 18:2975-2986

29. Kouidi E, Grekas D, Deligiannis A, Tourkantonis A: Outcomes of long-term exercise training in dialysis patients: comparison of two training programs. Clin Nephrol 2004, 61:S31-S38.

30. Pupim LB, Flakoll PJ, Levenhagen DK, Ikizler TA: Exercise augments the acute anabolic effects of intradialytic parenteral nutrition in chronic hemodialysis patients. Am J Physiol Endocrinol Metab 2004, 286:E589-E597.

31. Majchrzak KM, Pupim LB, Flakoll PJ, Ikizler TA: Resistance exercise augments the acute anabolic effects of intradialytic oral nutritional supplementation. Nephrol Dial Transplant 2008, 23:1362-9.

32. Copley JB, Lindberg JS: The risks of exercise. Adv Ren Replace Ther 1999 6:165-171.

33. Moissl U, Wabel P, Chamney PW, Renders L, Bosy-Westphal A, Korth O, Müller MJ: Validation of a bioimpedance spectroscopy method for the assessment of fat free mass. NDT plus 2008, 1:ii215.

34. Wieskotten S, Heinke S, Wabel P, Moissl U, Becker J, Pirlich M, Keymling M, Isermann R: Bioimpedance-based identification of malnutrition using fuzzy logic. Physiol Meas 2008, 29:639-54.

35. Theodorakis Y, Laparidis K, Kioumourtzoglou E, Goudas M: Combined effects of goal setting and performance feedback on performance and physiological response on a maximum effort task. Percept Mot Skills 1998, 86:1035-1041.

36. Segura-Ortí E: Exercise in haemodyalisis patients: a literature systematic review. Nefrologia 2010, 30:236-46.

37. Verschell M: Low intensity exercise as a treatment intervention in obese adults. In Handbook of obesity intervention for the lifespan. Edited by James LC, Linton JC, Linton C. New York: Springer; 2009:103-114.

38. Ninot G: Psychological outcome of exercise in patients with chronic disease. Science \& Sport 2013, 28:1-10.

39. American Thoracic Society: ATS statement: guidelines for the six-minute walk test. Am J Respir Crit Care Med 2002, 166:111-117.

40. Ware JE, Sherbourne CD: The MOS 36-item shortform health survey (SF-36): I. conceptual framework and item selection. Med Care 1992, 30:473-483.

41. McHorney CA, Ware JE, Raczek AE: The MOS 36- item shortform health survey (SF-36): Il. psychometric and clinical tests of validity in measuring physical and mental health constructs. Med Care 1993, 31:247-263.

42. Garratt AM, Ruta DA, Abdalla MI, Buckingham JK, Russell IT: The SF-36 health survey questionnaire: an outcome measure suitable for routine use within the NHS. BMJ 1993, 306:1437-1440.

43. Mingardi G, Cornalba L, Cortinovis E, Ruggiata R, Mosconi P, Apolone G: Health-related quality of life in dialysis patients: a report from an Italian study using the SF-36 health survey: DIA-QOL group. Nephrol Dial Transplant 1999, 14:1503-1510. 
44. Deschamps T, Magnard J, Cornu C: Postural control as a function of time-of-day: influence of a prior strenuous running exercise or demanding sustained-attention task. J Neuroeng Rehabil 2013, 10:26.

45. Huynh H, Feldt LS: Conditions under which mean square ratios in repeated measures designs have exact F-distributions. J Am Stat Assoc 1970, 65:1582-1589.

46. Huynh $H$, Mandeville GK: Validity conditions in repeated measures design. Psychol Bull 1979, 86:964-973.

47. Alem AM, Sherrard DJ, Gillen DL, Weiss NS, Beresford SA, Heckbert SR, Wong C, Stehman-Breen C: Increased risk of hip fracture among patients with end-stage renal disease. J Am Soc Nephrol Kidney Int 2000, 58:396-399.

doi:10.1186/1471-2369-14-259

Cite this article as: Magnard et al:: Effects of a six-month intradialytic physical ACTIvity program and adequate NUTritional support on protein-energy wasting, physical functioning and quality of life in chronic hemodialysis patients: ACTINUT study protocol for a randomised controlled trial. BMC Nephrology 2013 14:259.

\section{Submit your next manuscript to BioMed Central and take full advantage of:}

- Convenient online submission

- Thorough peer review

- No space constraints or color figure charges

- Immediate publication on acceptance

- Inclusion in PubMed, CAS, Scopus and Google Scholar

- Research which is freely available for redistribution 